\title{
The Mother Tongue Education Status and Ecological Diversion in Chinese Colleges
}

\author{
Qian Guo \\ Faculty of Liberal Arts, Northwest University, Xi'an , 710127
}

Keywords: Mother tongue education; Ecology; Sustainable education

\begin{abstract}
In the globalized cultural competition, the mother tongue increasingly stands out the importance as the carrier to inherit culture and spread civilization, but mother tongue education in institutions of higher learning is caught in the extensive disputes and "awkward" mud puddle, showing the pessimistic status quo. To reconstruct the paradigm of mother tongue education in institutions of higher learning by using ecological theory and promote harmonious and sustainable development of mother tongue education by virtue of comprehensiveness, association and balance is an innovative road that is attemptable.
\end{abstract}

In the irreversible globalized wave, various countries treat domestic mother tongue education in institutions of higher learning as an increasingly important public basic course. No matter in the USA, Hong Kong or Taiwan, mother tongue education occupies an important position in college education and it is brought into the required course system to safeguard it in the system. In China, mother tongue education in institutions of higher learning is undertaken by "College Chinese", especially for students who major in science, industry, agriculture and medicine. College Chinese is one of uncommon the school-required courses with the direct purpose of mother tongue education. According to the investigation on students' mother tongue level in College Chinese in recent years, it can be observed that from theoretical study to classroom practice and from internal support to external environment, College Chinese actually is kept in the "awkward" situation. The mother tongue education effects are also anxious.

By reviewing the history of mother tongue education, since the Revolution of 1911, "Freshman Chinese" course was established under the advocate of Cai Yuanpei. This was the Chinese language course that makes the current College Chinese educators and scholars admire its brilliance and sigh with its fade. "Freshman Chinese" established by Tsinghua University was commonly completed by multiple teachers, including Zhu Zhiqing, Wen Yiduo, Shen Congwen, Yu Pingbo, Yang Shuda, Yu Guanying, Wang Yao and $\mathrm{Wu}$ Zuxiang, who taught the most brilliant parts in their classroom. Students also could gain knowledge, enjoyment and scholarship approach in the classroom. On the other hand, the setting of freshman Chinese aimed to compensate for vernacular Chinese, pointing to fill a vacancy in scholarship enlightenment and reading.

After that, College Chinese has been paused for a long time until Mr. Kuang Yaming and Mr. Su Buqing advocated the reestablishment of College Chinese - the course is specific to students in non-Chinese major. The original intention of establishing such a course was to make up a missed lesson. At that time, most of students who were admitted to the college had the weak Chinese foundation. The direct purpose of establish such a course was to make up a basic course of Chinese. Guided by such an educational idea, it is enough that new teachers or young teachers make up Chinese knowledge and there is no need for famous professors giving a lesson in person. The reopening of College Chinese has already had 40 years. More and more colleges have joined, so that it is present in flourishing. However, College Chinese has been kept in the "awkward" situation for a long time, so that paradigm of mother tongue education falls into disorder.

First of all, in terms of one dimension, lagging theoretical study and confusion of College Course can't provide the powerful intelligent support for educational practice. "There are 1745 papers with the title of 'College Chinese' including 720 papers with the theme of humanity...There is the major deviation in the research direction of papers." ${ }^{[1]}$ Nearly half of College Chinese studies focus on the humanism of the course, but there is no consistent opinion. The confusion of theoretical studies is related to the priori one dimension preset of theoretical study in College Chinese. 
Secondly, in terms of utilitarian, College Chinese is considered as a dispensable course that is established for purposefulness and is stopped for uselessness. College Chinese is treated as a directly effective tool to make up a missed lesson for literature class, literacy class, writing class, common sense in literature and history, basic linguistics, outline of sinology and ancient Chinese. College Chinese just compensates for knowledge shortage of students. What's more, it may be changed for influences of sociocultural trends and public opinions. As a matter of fact, as the important channel of mother tongue education, College Chinese isn't as equal as College English, which is also a public basic course. The establishment is often measured by the utilitarian scale. Under the guide of utility, it is difficult for College Chinese to attract more excellent teachers and scholars indulging themselves in study.

At last, in terms of closeness, as an important channel of mother tongue education, College Chinese is relatively closed. First of all, College Chinese is disconnected with Chinese education in junior and senior high schools. College Chinese is indifferent to changes of high school Chinese textbooks and college entrance examination contents, but it fails to integrate with the existing Chinese education of students. In contents chosen by College Chinese, they may be repeated with high school Chinese. On the one hand, the explanation mode in the College Chinese classroom is highly identical with high school Chinese. Characters, words, structure and induction which are called as "high-four Chinese" are focused. On the other hand, it emphasizes the obvious distinction between College Chinese and high school Chinese, thus students may get caught in the separation between the manner and content, so as to not know what to do. Furthermore, it is hard for College Chinese to advance with times. In self-closeness, it ignores the dramatic changes in the outside world. In recent years, the network greatly changes the lifestyle and thinking mode of students. Therefore, if College Chinese still sticks to convention and constantly repeat itself, it just makes students reject it for tiredness. Besides, the teaching practice of College Chinese is often based on self-comprehension of teachers. Part-time teachers often exceed full-time teachers, while teaching contents often focus on research contents of full-time teachers.

\section{Ecology is the Subject to Study the Interaction between Organisms and Their Environment}

They are inseparable and correlative in the entire ecosystem. Based on it, "the world is the organic integrity composed of the relational network. Everything in reality is internally associated. All units or individuals are composed of relations. In this integrity, things as participants and relations between things exist in reality. The change of anything inevitably will change the complicated relational network. The mutually contained relation is a kind of internal organic association, instead of mechanical internal interrelation between entities." ${ }^{,[2]}$ If the higher education is considered as the ecosystem, College Chinese, as the main carrier of mother tongue education in institutions of higher learning, has the intimate relation with the overall system, other subjects and courses. The association is mutual, dynamic and multi-dimensional.

College Chinese can form the benign "mutualism and competition" with other courses in ecology of higher education. "Mutualism" is the positive reciprocal relation between two different individuals. It can increase fitness of both parties. ${ }^{[3]}$ As the main channel of mother tongue education in higher education, the connection and gaming process between College Chinese and "node" with other courses in the higher education system can be considered as the process of mutual acceptance, mutual affirmation or mutual dependence, thus mutualism between mother tongue education and other courses can be constructed. At the same time, College Chinese which is the main carrier of mother tongue education also can form the mutual competitive relation with other courses. On the one hand, it is the competition for limited class hour resources. Particularly, there is the wane and wax between public basic courses. On the other hand, the competitive process also makes the important channel of mother tongue education-College Chinese gain its professional positioning, theoretical range and living space from the traditional Chinese education, thus it will develop towards the more professional direction. Only to constantly attempt and explore in competition can College Chinese advance with the times, point to the current malpractice, and spark with vitality and energy of mother tongue. In addition, the mutualism and competition 
between College Chinese and other courses in different educational ecological system or subsystem will be present in different states, so as to reach the movement balance. By taking integrated colleges, vocational education colleges or colleges of science and engineering as examples, even if in the same kind of colleges, they will adjust and change under the different internal and external environment action, hoping to realize the dynamic balance and seek for the overall development.

Mother tongue education in ecology-oriented transformation uses life as the core value. The main idea of the mankind has already resulted in the serious ecological crisis. The prevalence and inundation of instrumental rationality make the indifference to life become common in the ecosystem of higher education. Ecological crisis promotes the reflection on the relation between man and nature and also advocates the reflection on educational thought. "Ecological crisis in essence is the crisis between man and natural relation. It promotes the tide of ecological education and development of ecological education movement, revealing the ecological tendency of the world education. Sustainable development strategy is the fundamental measure to realize educational ecology. The ecological tendency of future education is consistent with the gradual construction and ecological civilization in the future." ${ }^{[4]}$ Instrumental rationality often considers mother tongue flattening as one of instruments. In fact, it is extremely precious to understand culture loaded by mother tongue and mother tongue exploration on human life and spirit. Moreover, this should be particularly advocated in the mother tongue education. The process that students study mother tongue is the process of vital movement. To respect and cherish life is the valuable treasure contained by Chinese mother tongue. Unfortunately, traditional mother tongue education often neglects the most fundamental starting point of mother tongue education.

"Education must appeal to vital movement. It means that education is the process depending on the special spiritual vital movement of mankind. It is finally or fundamentally realized by the life with integrity, mobility and growth(innovation)." ${ }^{[5]}$ No matter for life worry and poetic expression in traditional poems, human relationship in traditional novels, ridiculousness and penetrating description in different forms of life, new-type characters and literary form from Vernacular Movement or reflection and revelation on living state of mankind in contemporary prose and novels, mother tongue is always concentrated on the reflection and heart of awe on the life. It doesn't mean mother tongue has deviation, but mother tongue education does it. With the entry point of the man and nature, whether the path of guiding mother tongue education can make students go deep in the core of mother tongue, become easy to comprehend respect and reflection on life brought by mother tongue, and become easy to understand the beauty and existence of mother tongue, so as to have the independent reflection on life of other people and the nature. The process indeed can enhance and improve mother tongue capacity.

Moreover, the continuous concern and reflection on the life exactly can be considered as the important core in traditional Chinese culture. Mother tongue gathers the cultural print and spiritual venation. In the study process of mother tongue, it is also the "sedimentation" and experience on traditional Chinese culture. Without the profound life identity and comprehension on mother tongue, the value of mother tongue education will be seriously underestimated. To comprehend a language seems to comprehend life care and a lifestyle. Chinese is not a tool that can be applied or abandoned at random. Chinese is completely integrated with human life. It is an indispensable part in human survival. The process of studying Chinese should be the conversation process of dimension between man and themselves, especially for higher Chinese. It is the process to explore life, recognize oneself and look for the significance. In a sense, mother tongue education inevitably will become the lifelong education.

Furthermore, mother tongue education definitely contains the construction and balance of learning ecology. "George Siemens thinks that learning ecology is the environment to promote and support formation and development of the community. The ecosystem has the same features with the natural ecosystem: Mutually crossing community of various interests; Mutual benefit of each member; Constant evolution and development; Self-organization and management." ${ }^{[6]}$ Colleges construct the new mother tongue education paradigm in colleges. The construction and balance of learning ecology can be considered as the new breakthrough direction, thus it proposes the higher 
requirements for students and teachers. Learning is the precondition that the mankind constantly makes progress. In terms of students, study in colleges destroys the logical framework of the existing exam-oriented education, gains and operates information in learning ecology, promotes energy operation, and maintains the balance of learning ecology. To participate with the identity of subjectivity perhaps can bring more feasible mother tongue education. In learning ecology, students should combine into several learning communities based on interest and consider them as nodes in the learning ecology network. Each learning community is the basic unit of information, knowledge and energy transfer. The common learning activities of students constitute in the energy power in learning ecology. In terms of teachers, the construction of learning ecology means the diversified classroom teaching mode. It can create and provide more choices for students and support interests and demands of different student groups to capacity, doing something with a purpose. Teachers are also kept in the subjective status in the students' ecology. This greatly improves teachers' enthusiasm and positivity. The benign knowledge sharing, resource exchange and collaboration between teachers and students can transform, transfer and update substances, resources and energy in learning ecology and look for the balance in dynamics.

From the perspective of individuals, learning mother tongue is the basic power. For the national countries, mother tongue is the embodiment and cohesion of natural culture power. Mother tongue education undertakes the important cultural responsibilities and cultural missions. Under the perspective of ecology, it is necessary to survey higher education of mother tongue, construct the new paradigm of mother tongue education in colleges, return to the life perspective, and construct the learning ecology, thus students will have the innovative criticism and independent thinking ability in "spirit maturity" in institutions of higher learning. Meanwhile, they will inherit culture, complete self-construction and selection in the spiritual independence and free direction, and expand the new era and new view of culture.

\section{References}

[1] He Eryuan and Liu Wenju, the History, Status and Direction of College Chinese Study [J], Chinese Teaching Communication, 2011(2): 9

[2] He Zubin, Review of Ecological Study on the Higher Education[J], Journal of Guangxi Normal University, 2005(1): 124

[3] [Britain] Mackenzie, Ecology[M], translated by Sun Ruyong, Beijing: Science Press, 2000, 119 ;

[4] Huang Zhicheng, the New Thought and Idea of International Education[M], Shanghai: Shanghai Educational Publishing House, 2009: 244;

[5] Guo Sile, the Influences of Classical Science on Education and the Conflict with Educational Life Mechanism[J], Educational Study, 2003(2): 15;

[6] Zhang Lixin and Zhang Lixia, the Design and Development of Ecological Virtual Environment[M], Beijing: Science Press, 2011:7

\section{About the author}

Guo Qian(1981-), female, Doctor of Literature, Northwest University in China, research direction: mother tongue teaching, ancient Chinese literature and culture 